\title{
Clínica ampliada na atenção básica e processos de subjetivação: relato de uma experiência
}

\section{I ${ }^{1}$ Ana Cristina Sundfeld I}

Resumo: A proposta da Estratégia de Saúde da Família (ESF) privilegia ações de promoção à saúde, desenvolvidas pela equipe de profissionais junto com a comunidade. $\mathrm{Na}$ imanência desse coletivo, encontramos linhas disparadoras de processos reflexivos que podem liberar a produção de um saber-fazer criativo. Neste sentido, a inserção da psicologia nos Núcleos de Apoio à Saúde da Família (NASF) pode contribuir para a efetivação de uma clínica ampliada na rede básica, crítica aos modelos ditos saudáveis, na maioria das vezes ortopédicos e modeladores, aberta a experimentações e ocupada em religar clínica-políticaprodução de modos de vida. Neste artigo problematizamos algumas demandas dirigidas à psicóloga integrante do NASF pelas equipes da ESF, sua produção e implicações ético-políticas para o exercício da clínica e processos de subjetivação resultantes. Trata-se de um estudo de caso que buscou percorrer e mapear nos discursos possíveis interlocuções e agenciamentos, cujas expressões são traduzidas como demanda para os profissionais da saúde. Em muitos casos, tais enunciados exprimem considerações morais, formas idealizadas de saúde e bem-estar. Apostamos que a construção da clínica é produto de um coletivo desejante, capaz de resistir aos mecanismos de captura e disciplinarização da vida. Este trabalho propõe que, a partir das provocações do cotidiano, a equipe dialogue, questione e se fortaleça, para afirmar formas de existir saudáveis e livres de padrões preestabelecidos.

> Palavras-chave: saúde da família; psicologia; clínica ampliada; subjetividade.

\author{
1 Professora do Curso de \\ Psicologia da Universidade \\ Paulista (UNIP), Mestre \\ em Psicologia Clínica pela \\ Pontifícia Universidade Católica \\ de Campinas (PUCCAMP). \\ Endereço eletrônico: \\ acsundfeld@uol.com.br
}


O Programa de Saúde da Família (PSF) foi proposto em 1994 pelo Ministério da Saúde, embora alguns municípios (Ceará, Niterói-RJ, Itacarambi-MG), com suas devidas particularidades, já abrigassem experiências neste sentido. Diante dos desafios da consolidação dos princípios do Sistema Único de Saúde (SUS) universalidade de acesso, integralidade da assistência, descentralização políticoadministrativa e participação da comunidade -, o PSF foi concebido para atuar como uma célula organizadora, dialógica, capaz de tecer os fios que compóem as redes da assistência à saúde. Podemos afirmar que este programa ganhou uma amplitude que o transformou em uma Estratégia de reorientação do modelo assistencial, transcendendo as limitações de um programa setorial de saúde (ANDRADE; BARRETO; BEZERRA, 2006).

Compreendemos a Estratégia de Saúde da Família (ESF) como:

um modelo de atenção primária, operacionalizado mediante estratégias/açôes preventivas, promocionais, de recuperação, reabilitação e cuidados paliativos das equipes de saúde da família, comprometidas com a integralidade da assistência à saúde, focado na unidade familiar e consistente com o contexto socioeconômico, cultural e epidemiológico da comunidade em que está inserido (ANDRADE; BARRETO; BEZERRA, 2006, p. 804).

A atenção primária prioriza uma abordagem preventiva e de promoção à saúde, contrariando o foco na queixa/sintoma e na ação curativa centrada no médico para a produção de uma escuta, de um vínculo e de um fazer associado ao coletivo de profissionais da saúde e usuários. O principal objetivo da ESF é a promoção da saúde, embora ações de assistência possam ser desenvolvidas dentro dos recursos disponíveis nas Unidades Básicas de Saúde, pois:

a assistência está contida na promoção da saúde que é uma ação mais ampla que a assistência. Mas é fundamental entender que ao se assumir a promoção da saúde como objetivo principal, ela vai direcionar a assistência que é prestada na atenção básica e influenciar diretamente os outros níveis de atenção, uma vez que se concebe o PSF como estratégia estruturante de todo o sistema (SUCUPIRA, 2003, p. 12).

A promoção da saúde moderna possui como marco inaugural o relatório Lalonde, produzido no Canadá em 1974, em um contexto de crise do Estado de Bem-Estar Social que enfrentou a escassez de recursos para atender às necessidades da população. $\mathrm{Na}$ década de 70 , o ministro canadense Lalonde investigou a causalidade do processo saúde-doença no país e constatou que os 
estilos de vida e ambiente eram responsáveis por oitenta por cento das causas das doenças. O relatório Lalonde sugeriu que as seguintes dimensões fossem observadas na elaboração das políticas de saúde: o ambiente, a biologia humana, os estilos de vida e o sistema de saúde (WESTPHAL, 2006).

A promoção da saúde obteve repercussões e reconhecimento internacional ao longo dos anos. As conferências internacionais de promoção de saúde, patrocinadas pela Organização Mundial de Saúde, produziram importantes discussōes e estratégias para o desenvolvimento da promoção em diversos países.

Na conferência realizada em Alma-Atá (1978), a saúde foi pela primeira vez reconhecida como um direito e a promoção da saúde articulada à autonomia e emancipação dos sujeitos. A conferência de Otawa (1986) resultou na Carta de Otawa, documento redigido pelos profissionais, importante marco conceitual da promoção de saúde. Esta carta propõe um conceito de saúde amplo, compreendida como "bem-estar físico, mental e social". Afirma que a saúde está ligada à complexidade do ser humano situado no mundo, capaz de identificar os determinantes da saúde e agir sobre eles. A capacitação do coletivo é incentivada no sentido de ampliar sua participação na construção das políticas públicas. O documento aponta ainda a importância da integração entre os diversos setores (políticos, econômicos, sociais, culturais, ambientais, etc.) para a promoção da saúde (ibidem).

Outras conferências consolidaram recomendaçōes e definiram prioridades para a promoção da saúde. A partir das conferências e de estudos realizados na área, podemos afirmar os seguintes princípios para a promoção da saúde: a) concepção holística da saúde; b) busca da equidade, ou seja, compromisso com a justiça social que garanta o acesso da população aos serviços; c) Intersetorialidade ou convergência de saberes e fazeres no intuito de superar a fragmentação das políticas públicas; d) participação social visando a autonomia das comunidades, valorização do conhecimento popular e respeito pelo local; e) a sustentabilidade (ibidem).

Tais princípios são norteadores das produções e práticas da ESF na perspectiva da promoção da saúde. Temos então as seguintes implicações: ampliação do conceito de saúde; compromisso com a equidade; investimento nas relações de troca entre profissionais, profissionais e comunidade e, finalmente, criação de parcerias entre os recursos da região; construção de vínculos com a comunidade a partir do conhecimento das necessidades do território e enfrentamento conjunto 
das dificuldades, visando a autonomia da população e valorização do saber-fazer local; preocupação com a sustentabilidade.

A adoção destes princípios pressupõe a construção de um novo processo de trabalho ancorado principalmente em duas açōes: a mudança de atitude dos profissionais e a gestão participativa da comunidade. Mais do que recursos técnicos, os trabalhadores em saúde necessitam produzir formas de subjetivação capazes de

constituir uma nova ética entre estes mesmos profissionais baseada no reconhecimento que os serviços de saúde, são, pela sua natureza, um espaço público, e que o trabalho neste lugar deve ser presidido por valores humanitários, de solidariedade e reconhecimento de direitos de cidadania em torno da assistência à saúde (FRANCO; MERHY, 2006, p. 83).

As ações de saúde da ESF são desenvolvidas por uma equipe composta por um médico generalista, um enfermeiro, um auxiliar de enfermagem e quatro a seis agentes comunitários de saúde (ACS). Algumas equipes contam ainda com um dentista e um técnico em odontologia. Cada equipe é responsável por um determinado território, onde residem de 800 a 1.000 famílias. Dentre as intervençōes realizadas, temos a visita domiciliar, grupos educativos e atendimentos clínicos com médicos e enfermeiros. A atuação da equipe se dá junto à família, cuja dinâmica deve ser compreendida dentro da singularidade sócio-histórica-cultural-econômica que a atravessa (BRASIL, s/d.).

A noção de território é fundamental para as ações de promoção de saúde, pois não se restringe a um espaço geográfico ou uma área física delimitada; trata-se de um espaço habitado, marcado pela subjetividade humana, pelas relações afetivas, relaçōes de pertencimento. O território é uma noção dinâmica, fluida, viva, pulsante, mutante. Conhecê-lo é condição para o planejamento das estratégias e políticas públicas. Portanto, é fundamental conhecer o local, quem habita o território, como, as relações afetivas, as trocas, as tensões, as necessidades enfim, o emaranhado que compõe o território e que, a partir de uma prática intersetorial, pode ser atendido em sua complexidade em direção à promoção de saúde (SACARDO; GONÇALVES, 2007).

A ESF se insere na comunidade através das visitas domiciliares dos agentes comunitários de saúde e de outros profissionais da equipe. $\mathrm{Na}$ condição de moradores da área de abrangência do serviço de saúde, os ACS convivem no cotidiano com a comunidade, participam dos problemas e dificuldades estruturais relacionados à saúde, educação, habitação, transporte, etc. Esta condição facilita 
a entrada dos ACS nos domicílios e seu papel de mediador entre os serviços de

saúde e a comunidade. Nas visitas são reforçadas as ações de rotina, propiciando o controle social que ao mesmo tempo se aproxima de uma fiscalização da vida privada dos usuários, seus hábitos e estilos de vida. Neste caso, percebemos uma fronteira tênue que por vezes mistura orientações técnicas com intervençôes de caráter normativo e moral. Apesar de tais riscos, o acesso dos ACS à comunidade também proporciona espaços de troca e diálogo potencialmente emancipatórios (COHN; NAKAMURA; GUTIERRES, 2009).

A promoção de saúde está vinculada à autonomia dos sujeitos na produção da saúde, porém é associada a noções como qualidade de vida e estilos de vida saudáveis, que estão sujeitas a funcionar de modo prescritivo, indutivo e normalizador. $\mathrm{O}$ princípio da autonomia indica uma abertura à convivência com o outro, pautada em valores que respeitem a alteridade e a livre escolha. Implica a construção de espaços coletivos de troca que possibilitem o enriquecimento da comunidade e dos profissionais envolvidos, através do conhecimento do cotidiano, das estratégias locais, das possibilidades de cada sujeito.

A expansão do acesso e a entrada do profissional nos domicílios das famílias possibilitam um contato próximo com a comunidade e a escuta de novas demandas que chegam ao profissional e ao serviço. Contudo, tais demandas muitas vezes transcendem a organização e estrutura do serviço, desafiando o instituído, inclusive o saber-fazer do profissional.

Franco e Merhy (2006) direcionam uma crítica a ESF, ao apontarem que a mudança na forma ou estrutura do serviço é insuficiente para produzir novos processos de trabalho. Geralmente, há uma tendência no sentido de transpor o modelo centrado no médico, a fragmentação, a vocação curativa e individual para o trabalho em equipe. Os autores ressaltam que o caráter prescritivo do programa tende a engessar a criatividade dos profissionais e impedir a formulação de arranjos criativos e autônomos. Uma alternativa capaz de combater a reprodução de velhas práticas inócuas é o investimento na mudança dos processos de trabalho de modo que cada profissional atue com o máximo de sua potência num trabalho vivo em ato, que seja:

o acolhimento ao usuário, através da escuta qualificada, o compromisso de resolver seu problema de saúde, a criatividade posta a serviço do outro e, ainda, a capacidade de estabelecer vínculo, formam a argamassa da micropolítica do processo de trabalho em saúde (FRANCO; MERHY, 2006, p. 121). 

Núcleo de Apoio à Saúde da Família (NASF), com o objetivo de ampliar as ações da atenção básica no que tange à abrangência e resolutividade. O NASF reúne profissionais de diversas áreas do conhecimento que atuam de forma integrada com as equipes de saúde da família a partir das demandas identificadas em conjunto. A composição do NASF é definida pelos gestores municipais e varia de acordo com as necessidades do território (BRASIL, 2008). O processo de trabalho prioriza:

(a) Atendimento compartilhado para uma intervenção interdisciplinar, com troca de saberes, capacitação e responsabilidades mútuas, gerando experiência para ambos os profissionais envolvidos.

(b) Intervenções específicas do NASF com usuários e famílias encaminhados pela equipe de SF, com discussões e negociação a priori entre os profissionais responsáveis pelo caso, de forma que o atendimento individualizado pelo NASF se dê apenas em situaçōes extremamente necessárias;

(c) Ações comuns nos territórios de sua responsabilidade, desenvolvidas de forma articulada com as equipes de SF e outros setores. Como, por exemplo, o desenvolvimento do projeto de saúde no território, planejamentos, apoio aos grupos, trabalhos educativos, de inclusão social, enfrentamento da violência, ações junto aos equipamentos públicos (escolas, creches, igrejas, pastorais, etc.) (BRASIL, s/d[a]).

O NASF funciona a partir da perspectiva de apoio matricial, ou seja, o conjunto de profissionais contribui com suas especialidades e experiências para complementar a equipe de referência - no caso, a equipe multiprofissional de saúde da família - e promover, em parceria, estratégias de intervenção e compartilhamento da responsabilidade pela clientela atendida. A perspectiva interdisciplinar favorece a criatividade dos profissionais envolvidos na construção dos dispositivos na atenção básica (BRASIL, 2009).

A clínica ampliada é a diretriz de atuação dos profissionais da saúde. Consiste basicamente na articulação e diálogo de diferentes saberes para compreensão dos processos de saúde e adoecimento e na necessidade de inclusão dos usuários como cidadãos participantes das condutas em saúde, inclusive da elaboração de seu projeto terapêutico (BRASIL, 2009). Nesse contexto, a clínica existe em interface com a política, pois o encontro ocorre entre modos de subjetivação fabricados no coletivo, no plano social, em que o instituído e o novo são forças em movimento:

a clínica, então, é sempre uma interação complexa entre sujeitos. Apesar de todas as proteções institucionais, a clínica efetivamente é um encontro entre dois Sujeitos 
singulares. Um profissional e um "doente", uma equipe e um "doente", uma equipe

e um Sujeito coletivo (uma família ou uma comunidade, etc.). Neste modelo de análise entendemos a clínica com uma dimensão política e subjetiva muito forte (CUNHA, 2005, p. 46).

O Projeto Terapêutico Singular é produto da discussão coletiva dos profissionais e do compartilhamento com o usuário, pois as condutas terapêuticas e as metas são negociadas. Baseia-se na singularidade do usuário, na receptividade das diferenças que transcendem os diagnósticos e sua inclinação para igualar os sujeitos (BRASIL, 2009).

Finalmente, a clínica ampliada prevê, de acordo com a necessidade dos usuários, a articulação entre os serviços de saúde e outros setores e políticas públicas tidos como recursos para promoção de saúde, por compreender que esta se constitui num agenciamento de vetores sócio-político-cultural-econômico num mesmo plano de imanência.

Este artigo pretende compartilhar um recorte da experiência da autora como psicóloga de uma equipe NASF, lotada na região sudeste da cidade de São Paulo, problematizando algumas demandas trazidas pelas equipes da ESF, sua produção e implicações ético-políticas para o exercício da clínica e os processos de subjetivação atuantes.

\section{A Psicologia na Saúde Pública: novos espaços, velhos desafios}

De acordo com Dimenstein (1998), a inserção dos psicólogos no âmbito das instituiçôes públicas de saúde teve início no final da década de 70. É nesta década que o modelo médico gradativamente se caracterizou como um modelo privativista, orientado pelo lucro, com ênfase numa prática médica curativa, individual e assistencialista, em detrimento da saúde pública. Particularmente no setor da saúde mental, que absorveu os primeiros psicólogos, surgiram questionamentos relativos ao modelo hospitalocêntrico, devido aos efeitos danosos das internações prolongadas e suas implicações em termos de eficácia e consequências éticas. As propostas de desospitalização da assistência médico-psiquiátrica ganharam impulso, inspiradas em movimentos de reforma psiquiátrica desenvolvidos na década de 40 nos EUA e Europa, dentre os quais destacamos a Psicoterapia Institucional e as Comunidades Terapêuticas, a Psiquiatria de Setor Francesa e a Psiquiatria Preventiva Norte Americana, além da Antipsiquiatria e a Psiquiatria 
Democrática Italiana. No intuito de desenvolver redes de serviços substitutivos ao hospital, ao mesmo tempo mais eficazes e de menor custo social, tornouse necessária a formação de equipes multiprofissionais, comprometidas com as transformações exigidas para a desospitalização, como a criação de serviços alternativos extra-hospitalares. Até então, a categoria médica era predominante nas equipes de saúde, que passou a contar com outros profissionais, dentre os quais, o psicólogo.

Dimenstein (1998) afirma que a crise econômica e social no Brasil na década de 80 também contribuiu para a entrada dos psicólogos nos espaços institucionais públicos, pois o mercado dos atendimentos privados sofreu uma restrição que provocou desequilíbrio entre a oferta e a procura dos serviços de psicologia. Nesse contexto, o setor público passou a ser um atrativo tanto para os profissionais recém-formados quanto para aqueles que já atuavam no mercado privado há algum tempo. Deste modo, o psicólogo passou a ocupar espaços como hospitais psiquiátricos e gerais, postos e centros de saúde, maternidades, etc. Portanto, o tempo de atuação dos psicólogos nas instituições públicas de saúde é relativamente pequeno.

Com efeito, a reforma no modelo de atenção à saúde, consolidada com o SUS, ampliou a inserção de psicólogos nos serviços de saúde destinados à atenção primária, nos quais esses profissionais são responsáveis por atividades preventivas. As Unidades Básicas constituem espaços de promoção de saúde, que são potencialmente capazes de criar dispositivos voltados para a autonomia e o exercício coletivo de uma cidadania crítica e transformadora. Esta produção é um desafio que depende, sobretudo, de um olhar atento aos processos de subjetivação atuantes e às intervençôes propostas pelos profissionais e comunidade.

A atuação do psicólogo com os demais profissionais do NASF e com as equipes de saúde da família pressupõe a conexão da saúde mental às ações da saúde em geral, o desenvolvimento conjunto de estratégias de promoção e cuidados à saúde. Nesta perspectiva, os diversos especialistas são parceiros na fabricação e operacionalização de intervenções. Entretanto, este modo de operar é um desafio que supõe uma abertura para a desconstrução das formas tradicionais de pensar a saúde e sua produção. Neste processo, é possível conquistar um olhar que articule a complexidade do real, as inter-relaçôes constitutivas da subjetividade e os modos de existir dos sujeitos. 


\section{Percorrer, traçar, acompanhar: diferenciações e composições em movimento}

Habitar a experiência e acolher no percurso os movimentos, processos de expansão e contração, giros, saltos, voos. Com esta disposição, integramos a equipe do NASF. Nossa ideia era acompanhar o fluxo dos discursos e fazeres, conhecer o desafio das equipes, o vínculo com a comunidade, possibilidades de criação. Este texto apresenta um breve relato ou mapeamento das demandas trazidas pelas equipes e consequentes reflexões.

Trata-se de um estudo de caso que pretende descrever as experiências vividas no contexto das equipes e processos de trabalho a partir da problematização da demanda. Configura-se como um estudo exploratório, cujos dados foram coletados através da observação participante e registros de campo. É pertinente destacar que, nesta perspectiva, sujeito e objeto se implicam, tensionam juntos, se afetam, numa provocação às formas cristalizadas do pensamento, permanente convite a reinvenção de si e do mundo (GIL,2009).

O estudo de caso é uma metodologia que favorece o conhecimento da realidade do ponto de vista do contexto e das relações que o atravessam, ressaltando a dimensão complexa da pesquisa:

[...] trata-se de um método de observação, de construção de raciocínio e de relato de informações que entrelaça teoria com observaçōes de fatos, possibilitando a reflexão e a formulação de hipóteses, abrindo portas para novas descobertas, o que configura seu valor construtivo (CAPITÃO; WILLEMOR-AMARAL, 2007, p. 238).

A equipe de profissionais do NASF pertence a uma área da região sudeste da cidade de São Paulo e possui as seguintes especialidades: serviço social, fisioterapia, educação física, ginecologia e psicologia. Era responsável por 11 equipes de saúde da família, localizadas em três unidades de saúde. Nas reunióes mensais com as equipes, um profissional representante do NASF registrava e discutia as demandas trazidas, expectativas e possibilidades de intervenção. Nesses encontros, buscavase conhecer as condições da família e, sobretudo, o vínculo com a equipe. Nas reuniões semanais, os profissionais do NASF abordavam os casos indicados pelas equipes e a construção de estratégias era enriquecida pela troca de conhecimentos e experiências das especialidades envolvidas. O planejamento das ações do NASF não se constituía apenas ancorado nas discussões realizadas nas reuniões mensais. Por se tratar de demandas/situações em movimento, buscava-se a informação atualizada 
através do contato constante com as agentes comunitárias e demais profissionais da ESF, de modo que a comunicação não se restringia às reuniōes agendadas, mas acontecia no cotidiano das equipes e as intervençōes eram pactuadas.

Neste percurso, como especialista $p s i$, a autora recebia um alto número de demandas variadas que reuniam pedidos de avaliação psicológica, orientação e aconselhamento, cujos autores eram a escola, o conselho tutelar, os pais e a própria equipe de saúde. Exemplos transcritos de demandas relatadas em reuniōes: a) criança abandonada pelos pais, escola se queixa de agressividade; b) usuário com sintomas depressivos; c) problemas de relacionamento familiar; d) criança quer abandonar a escola; e) família comprometida emocionalmente; f) criança com crises nervosas; g) adolescente fora da escola por expulsão e "rebeldia"; h) criança apresenta medo de ir para escola, mãe refere professora agressiva; i) mãe relata dificuldades na educação dos filhos; j) criança com dor de cabeça e agitação, em acompanhamento neurológico; k) dificuldades de aprendizagem; l) criança hiperativa; m) síndrome do pânico; n) paciente etilista, família pede tratamento; o) falta de apoio e cuidado da família com o paciente idoso e com portador de déficit intelectual.

Era possível perceber diversas formas de sofrimento nas famílias, porém, muitas destas demandas eram produzidas em virtude de um desconforto ou desconcerto provocado nas equipes de saúde e/ou na escola. Ao qualificar a família como "problemática", responsável pelo adoecimento de um de seus membros por "comprometimento emocional" ou falta de "limites" na educação dos filhos, esses agentes não estariam adotando uma norma/modelo ideal de família como representante de uma organização saudável, em vez de indagar como se "estrutura" tal coletivo, quais suas necessidades, quais as condições de vida/ vínculos produzidas nas relações?. Afinal, não será este o sentido da Estratégia de Saúde da Família: transitar pelos territórios existenciais das famílias, conhecê-los, mapear sua geografia de hábitos, crenças, religiosidade, afetos e desejos para então potencializar em parceria modos mais tolerantes de convivência? (LANCETTI, 2009). Para operar nesta direção, tornou-se fundamental questionar a demanda trazida pelas equipes, no sentido de conhecer os mecanismos de sua produção, ou seja, indagar quais os norteadores que caracterizaram determinados comportamentos, gestos e hábitos como não saudáveis. Muitas vezes, o coletivo de profissionais percebia a presença de uma inclinação moral na abordagem dos 
casos e discussão de estratégias. Tais momentos se revelaram fundamentais na atuação do NASF com a equipe, e vice-versa, pois desmistificavam pré-conceitos e concepções de saúde cristalizadas, permitindo a revisão de posturas, intervenções e perspectivas de cuidado.

As queixas encaminhadas pela escola atualizam uma velha associação que remete ao início do século XX, quando acontece uma parceria entre a pedagogia e a medicina. O campo educativo desde então é atravessado por discursos de especialidades interessadas nos problemas de desenvolvimento infantil (psicologia, fonoaudiologia, psicopedagogia, psiquiatria, etc.). Esta aproximação entre a escola e os saberes psicológico e psiquiátrico atingiu o auge nos dias atuais, com o grande número de pedidos de avaliação psicológica e psiquiátrica, geralmente motivados por "mau comportamento", “condutas inadequadas", problemas de aprendizagem, suposta hiperatividade, agressividade, dentre outros. $\mathrm{O}$ sofrimento e as dificuldades cognitivas das crianças são decifrados, sobretudo, por uma visão de psiquiatria baseada num discurso biológico, em que os sintomas são expressões de desordens bioquímicas do cérebro. Este raciocínio reducionista despreza as relações da criança com o sistema escolar, a família e a sociedade. Logo entram em cena os psicofármacos, que se tornam “imprescindíveis" nas terapêuticas indicadas pelos especialistas. Assistimos consequentemente a crescente psiquiatrização do discurso escolar e a medicalização da infância:

É comum também que agentes das equipes escolares insistam em perguntar aos pais, quando se encontram diante de alguma manifestação não conhecida (ou não desejada) de uma criança que está em tratamento, se ela foi corretamente medicada naquele dia. Tais procedimentos nos permitem entrever que estão crentes de que a variação no uso do remédio é responsável pela variação dos comportamentos e estados psíquicos das crianças, e que esta não teria nenhuma relação com variações, mudanças ou experiências no interior do cotidiano escolar (GUARIDO, 2007, p. 157).

No entanto, a interlocução entre a saúde e a escola é imprescindível para a efetuação de uma política intersetorial capaz de articular os recursos existentes na comunidade. Percebemos que, no contexto pesquisado, as escolas abrigavam uma série de problemas relacionados às condições socioeconômicas do território como as más condições de habitação, alimentação, segurança, transporte, saneamento e exposição a situações de violência, fatores que desafiavam o cotidiano escolar e sua gestão. Neste cenário, as escolas não possuíam condições de qualificar a atenção pedagógica aos alunos. Além disso, eram poucos os recursos advindos das políticas 
públicas e de instituições de caráter não-governamental; a ESF tornava-se muitas vezes o único recurso assistencial para onde as demandas eram encaminhadas.

Os pedidos de avaliação, diagnóstico e tratamento não partiam somente da escola. As expressões de sofrimento e mal-estar eram trazidas pelos pacientes sob o rótulo de sintomas depressivos, crises nervosas e síndrome do pânico. $\mathrm{O}$ autodiagnóstico e a solicitação de medicação para suprimir o desconforto faziam parte da rotina nas visitas domiciliares dos profissionais. Curioso é perceber o atravessamento dos conhecimentos psi no cotidiano das famílias, seja na linguagem, seja na interpretação dos comportamentos e nomeação do mal-estar. De modo geral, as pessoas comunicavam um desejo de não sentir dor, de expulsar o desconforto, de entorpecer o corpo com medicamentos num congelamento das sensações e afetos, sintomas de uma certa contemporaneidade?

Nas visitas domiciliares, problematizávamos com os usuários e familiares os pedidos de medicalização e buscávamos alternativas no intuito de promover um olhar crítico sobre o uso do medicamento e a corresponsabilização pelo cuidado. Em alguns casos, havia a produção de novos modos de relação entre os familiares, outra sensibilidade e convivência eram possíveis. Nessas interações, as trocas favoreciam a todos: famílias, usuário e profissionais.

A autonomia é um princípio norteador da promoção da saúde que deve pautar as ações do NASF e da ESF. Ocasiona revisões amplas relativas ao conceito de saúde e seus cuidados e se traduz nos seguintes compromissos dos profissionais: interesse, escuta e respeito à singularidade e modos de vida dos usuários; revisão da tendência ao uso do poder que muitas vezes reproduz relações de dominação e opressão com os usuários; reconhecimento das limitaçôes do saber e da técnica e recusa das relações baseadas na autoridade e ilusão de um saber absoluto; observação da autonomia dos sujeitos como contraponto e manifestação da diversidade frente ao lugar da ciência como verdade, com seus modelos de normalidade e atração pelo universal; atenção à margem de tolerância da comunidade, da equipe e de si mesmo para a convivência com o exercício de autonomia dos sujeitos; questionamento dos efeitos das práticas na construção das subjetividades.

Nesta complexidade de atores, autores, fazeres e dizeres, era importante sustentar o compromisso ético de dizer não à medicalização e à moralização da vida. Afinal, assistimos ao crescimento desenfreado do consumo de medicamentos que despotencializam os sujeitos, incentivado pela mídia e por uma parcela da 
medicina associada à grande indústria farmacêutica. A moralização da vida produz apenas sujeitos fracos, separados de sua potência de pensar, sentir e viver, penalizados por um processo de culpabilização de seus hábitos, comportamentos, gestos e relações. Nestas circunstâncias, o combate consiste na afirmação de uma saúde não normativa, mas associada à autonomia e criatividade dos sujeitos, fortalecendo a cidadania e a multiplicidade de modos de vida. Por outro lado, os conhecimentos psicológicos podem tornar-se mecanismos voltados para a prescrição de modos de ser ou estilos ditos saudáveis de vida, sem que se leve em conta, entretanto, certos efeitos, como o enfraquecimento dos sujeitos e a colaboração com mecanismos de controle e disciplinarização. Nesta linha de ação, a comunidade é enfraquecida, chegando os sujeitos a serem imobilizados numa armadilha que supostamente representa a libertação ou o alívio do sofrimento.

As definições de doença que norteiam a formação dos profissionais da saúde geralmente traduzem a ideia de falta, desequilíbrio, desadaptação, relativas a uma visão normativa e idealizada de saúde, além de reafirmarem as dicotomias sujeito-ambiente e/ou psíquico-corpo. O conceito de saúde proposto pela Organização Mundial de Saúde ilustra esta tendência: Saúde é um estado de completo bem-estar físico, mental e social e não apenas a ausência de afecção ou doença. Nesta concepção, parece implícito um bem-estar como sinônimo de adaptação e ausência de conflitos. Consequentemente, o fenômeno saúde é reduzido a uma circunstância estática e artificial, em que a vida é imobilizada em suas contradições e em seu movimento (FRANCO; MERHY, 2006).

\section{A potência da clínica: habitar o mundo, criar paisagens, tecer modos de viver}

Não é fácil ser um homem livre: fugir da peste, organizar encontros, aumentar a potência de agir, afetar-se de alegria, multiplicar

os afetos que exprimem ou envolvem um máximo de afirmação. Fazer do corpo uma potência que não se reduz ao organismo, fazer do pensamento uma potência que não se reduz à consciência.

(DELEUZE,1998, p.75).

Ora, a formação do psicólogo é permeada por dicotomias conscienteinconsciente, sujeito-objeto, interior-exterior, indivíduo-sociedade, neutralidadeenvolvimento, mente-corpo. Além disso, privilegia um modelo psíquico 
universalizante, fortemente representado por perspectivas de desenvolvimento humano que modulam a saúde do sujeito, e desenham as margens e os limites de transgressōes possíveis. Embora gradativamente questionado, este modelo abstrato muitas vezes povoa as práticas dos profissionais, que (re)produzem formas de amar, pensar, desejar e viver. Preso a estas dicotomias, o profissional de psicologia atua a partir de um plano transcendente, limitado por representações artificialmente construídas que fundamentam procedimentos, técnicas e ideais insuficientes de subjetivação.

Consideramos, entretanto, que a subjetividade é produção incessante de novas paisagens, deslocamento e movimento, afirmação e desejo de diferença - portanto, impossível de qualquer totalização. $\mathrm{O}$ desejo de definir o homem, negando a transitoriedade que o atravessa, reflete um movimento de dominação tendente a minimizar a diferenciação produtiva que pulsa nos processos de subjetivação.

A disjunção entre sujeito e mundo, dentro e fora, oferece-nos a imagem do indivíduo como entidade separada, que sofreria a influência de fatores externos na composição de sua subjetividade individual. Rolnik (1997), no texto "Psicologia: subjetividade, ética e cultura”, utiliza a metáfora da pele para expor a indissociável relação entre o dentro e o fora na formação das paisagens subjetivas: "A pele é um tecido vivo e móvel, feito das forças/fluxos que compõe os meios variáveis que habitam a subjetividade: meio profissional, familiar, sexual, econômico, político, cultural, informático, turístico, etc. (p. 14)”.

A subjetividade ou o modo de ser sofre variações e está em movimento, construindo diferentes combinações a partir das forças que a atravessam. Formando dobras, a pele constitui um perfil de subjetividade provisório, que logo se desmancha e se transforma, provocada pela incidência de novos fluxos. A separação entre o dentro e o fora é uma falsa imagem: “[...] o movimento de forças é o fora de todo e qualquer dentro, pois ele faz com que toda e qualquer figura saia de si mesma e se torne outra. O fora é um sempre outro do dentro, seu devir" (ROLNIK, 1997, p. 15).

$\mathrm{O}$ indivíduo consciente - esse que aparece em alguns discursos psi como produção de um sujeito que define a realidade e constitui a si mesmo - é uma ficção que separa o indivíduo das forças/fluxos que o atravessam, ficção que fortalece os dualismos e polaridades que situam, por exemplo, o indivíduo 
de um lado e o social do outro. No entanto, com Deleuze e Guattari (2000), podemos dizer que "não existe enunciado individual, nunca há. Todo enunciado é o produto de um agenciamento maquínico, quer dizer, de agentes coletivos de enunciação" (p. 51). Este eu é, portanto, constituído, fabricado, inventado, a partir de uma orquestração de vozes diversas:

os enunciados não têm por causa um sujeito que agiria como sujeito da enunciação, tampouco não se referem a sujeitos como sujeitos de enunciado. $\mathrm{O}$ enunciado é o produto de um agenciamento, sempre coletivo, que põe em jogo, em nós e fora de nós, populações, multiplicidades, territórios, devires, afetos, acontecimentos (DELEUZE, PARNET, 1998, p. 65).

É, portanto, do complexo jogo de forças, composto de fluxos sociais, culturais, políticos, históricos, econômicos, estéticos, que a subjetividade é tecida:

a subjetivação é um processo de composição de modos de vida que passa a se definir prioritariamente pelos encontros de corpos, entendidos como contraçôes imanentes dos elementos ou forças que compõem um campo, em uma perspectiva experimental que recusa de forma radical qualquer dimensão transcendente (PEIXOTO JR., 2008, p. 80).

Os comportamentos, valores, modos de relação e estilos de consumo que compõem a subjetividade são produzidos no campo do social (GUATARRI; ROLNIK, 2000). Nele, os discursos referentes aos modos de subjetivação são legitimados através de dispositivos de poder e saber que os consideram discursos verdadeiros. Em outras palavras, as verdades do discurso são produzidas e exercem um papel regulador nas existências dos indivíduos:

Cada sociedade tem seu regime de verdade, sua "política geral" de verdade: isto é, os tipos de discurso que ela acolhe e faz funcionar como verdadeiros; os mecanismos e instâncias que permitem distinguir os enunciados verdadeiros dos falsos, a maneira como se sanciona uns e outros; as técnicas e os procedimentos que são valorizados para a obtenção da verdade; o estatuto daqueles que têm o encargo de dizer o que funciona como verdadeiro (FOUCAULT, 2006, p12).

Neste sentido, tais discursos mobilizam formas de viver, de desejar, de pensar que potencializam a liberdade do indivíduo e a afirmação da diferença ou favorecem um modo de ser submisso e escravo, obediente às formas aprisionadoras e preestabelecidas. Portanto, os processos de subjetivação estão mergulhados na rede de saberes e relações de poder que historicamente se constituem. Há nesta dinâmica uma capacidade de aderência entre seus elementos, mas também brechas capazes de liberar linhas de fuga da subjetividade (PEIXOTO JR., 2008). 
O modelo tradicional da clínica, como já dito neste trabalho, desconsidera a perspectiva da subjetividade como produto imanente ao tecido social e histórico, fabricada e modelada num plano de forças dinâmico, no qual agenciamentos ocorrem, compondo, num movimento de (des)construção, paisagens subjetivas. Separando o exercício da clínica dos processos de subjetivação, nega-se a interface clínica-política, pois:

definir a clínica em sua relação com os processos de produção de subjetividade, implica, necessariamente, que nos arrisquemos numa experiência de crítica/análise das formas instituídas, o que nos compromete politicamente (BENEVIDES, 2005, p. 23).

Como devolver a clínica ao campo produtivo do desejo? Como libertála da sobrecodificação dos enunciados que impede os devires? Eis o desafio: produzir uma clínica como espaço de experimentações, provocações, aberturas, movimentos instituintes, uma clínica de afirmação da vida.

Não basta lançar novas diretrizes para a saúde como o conceito de clínica ampliada, pois este pode apenas encobrir velhas práticas e procedimentos interpretativos. A reforma da assistência pressupõe a reforma do pensamento de seus atores: profissionais e comunidade e, sobretudo, um sim às incertezas e inventividade do cotidiano. Nesta direção, os serviços de atenção primária têm a potencialidade de funcionar como espaços de experimentação coletiva, associados à comunidade. A ampliação do espaço da psicologia nestes serviços, como no NASF, por exemplo, pode contribuir para a crítica e a desconstrução dos artifícios técnicos consolidados nas práticas e, neste sentido, a própria definição de clínica e os processos de subjetivação em curso tornam-se objeto de análise.

$\mathrm{O}$ que pode a clínica? O que ela produz em termos de subjetivação? Como provocar rupturas com o modelo de individualização dominante e inserir diferentemente o pensamento num plano de articulação com forças sócio-políticas que o atravessam? Como potencializar modos de intervenção libertadores e favoráveis à produção de um sujeito ativo, ao invés de reproduzir uma prática corretiva e alienante? A psicologia pode instigar uma escuta mais sensível e atenta às necessidades e dispositivos comunitários que, por sua vez, são capazes de provocar importantes indagações e rupturas ao saber-fazer estabelecido das equipes. Refletir o cotidiano com os atores envolvidos, contribuir para o fortalecimento dos vínculos e a criação de um espaço de resistência às formas 
de disciplinarização que se inserem nos processos de trabalho, nas relações e nos corpos. Enfim, apostar na construção de um coletivo desejante do exercício de uma clínica viva, pulsante, aliada aos deslocamentos e desvios, potências liberadoras de novos modos de habitar o mundo.

\section{Referências}

ANDRADE, L.O.M.; BARRETO, I.V.H.C; BEZERRA, R.C. Atenção primária à saúde e estratégia saúde da família. In: CAMPOS, G.W.S. et al. Tratado de saúde coletiva. São Paulo: Hucitec, 2006. p. 783-836.

BENEVIDES, R. A psicologia e o sistema único de saúde: quais interfaces?. Psicologia e sociedade. v. 17, n. 2, p. 21-25, mar/ago.2005.

BRASIL. Ministério da Saúde. Ações e Programas. Atenção básica e a saúde da família, s/d. Disponível em <http://dtr2004.saude.gov.br/dab/atencaobasica.php>. Acesso em: 26 out. 2009.

BRASIL. Ministério da Saúde. Ações e Programas. Portaria n¹54/GM, de 24 de janeiro de 2008, republicada em 04 de março de 2008. Disponível em < http://dtr2004.saude.gov.br/ dab/nasf.php > Acesso em: 26 out. 2009.

BRASIL. Ministério da Saúde. Açóes e Programas. Núcleo de Apoio à Saúde da Família NASF, s/d (a). Disponível em < http://dtr2004.saude.gov.br/dab/nasf.php>. Acesso em: 26 out. 2009.

BRASIL. Ministério da Saúde. Secretaria de Atenção à Saúde. Política Nacional de Humanização da Atenção e Gestão do SUS. Humaniza SUS: clínica ampliada e compartilhada. Brasília, DF, 2009. 64 p. (Série B. Textos Básicos de Saúde).

CAPITÃO, C.G.; VILLEMOR-AMARAL, A. E. A pesquisa com estudo de caso. In: BAPTISTA, M.N.; CAMPOS,D.C. Metodologias de pesquisa em ciências: análises quantitativa e qualitativa. Rio de Janeiro: LTC, 2007.

COHN, A.; NAKAMURA, E.; GUTIERRES, K.A. De como o PSF entrecruza as dimensões pública e privada da vida social. In: $\mathrm{COH}$, A. (Org.). Saúde da família e SUS: convergências e dissonâncias. Rio de Janeiro: Beco do Azougue, 2009, p. 141-167.

CUNHA, G. T. A construção da clínica ampliada na atenção básica. São Paulo: Hucitec, 2005. 206p.

DELEUZE, G.; GUATARRI, F. Mil platôs. $2^{a}$ ed. São Paulo: Editora 34, 2000. 91p. 1v.

DELEUZE, G.; PARNET, C. Diálogos. São Paulo: Escuta, 1998. 175p.

DIMENSTEIN, M.D.B. O psicólogo nas unidades básicas de saúde: desafios para a formação e atuação profissionais. Estudos de psicologia. ,v. 3, n. 1, p. 53-81,1998.

FOUCAULT. M. Microfisica do poder. $22^{\mathrm{a}}$ ed. Rio de Janeiro: Graal, 2006. 295p. 
FRANCO, T.B.; MERHY, E.E. Programa de Saúde da Família (PSF): contradições de um programa destinado à mudança do modelo tecnoassistencial. In: MERHY, E.E. et al. $O$ trabalho em saúde: olhando e experienciando o SUS no cotidiano. $3^{\underline{a}}$ ed. São Paulo: Hucitec, 2006. p. 55-124.

GUARIDO, R. A medicalização do sofrimento psíquico: considerações sobre o discurso psiquiátrico e seus efeitos na educação. Educação e pesquisa, São Paulo, v. 33, n. 1, p. 151-161, jan/abr.2007. Disponível em <http://www.scielo.br/pdf/ep/v33n1/a10v33n1.pdf >. Acesso em: 28 out. 2009.

GUATARRI, F.; ROLNIK, S. Micropolítica: cartografias do desejo. 6ª ed. Petrópolis : Vozes, 2000. 326p.

LANCETTI, A. Saúde mental nas entranhas da metrópole. In: LANCETTI, A. et al. Saudeloucura: Saúde mental e saúde da família. 2ª ed. São Paulo: Hucitec, 2009. p. 11-52 (Série Saúdeloucura n. 7).

PEIXOTO JR., C.A. A clínica da subjetivação como crítica da cultura. In: A Singularidade e subjetivação: ensaios sobre clínica e cultura. Rio de Janeiro: 7letras, 2008. p. 70-82. ROLNIK, S. Psicologia: subjetividade, ética e cultura. In: BARROS, R.B. et al. Saúdeloucura: subjetividade. Questões contemporâneas. São Paulo: Hucitec, 1997. p. 13-21 (Série Saúdeloucura, v.6).

SACARDO, D.P.S.; GONÇALVES, C.C.M. Território: potencialidades na construção de sujeitos. In: FERNANDEZ, J.C.A.; MENDES, R. (Org.) Promoção da saúde e gestão local. São Paulo: Aderaldo e Rothschild, 2007, p. 111-129.

SUCUPIRA, A. Marco conceitual da promoção da saúde no PSF. Sanare: Revista de Politicas Públicas, ano IV, p. 11-14, jan/fev/mar. 2003. Disponível em <http://www.esf.org.br>. Acesso em: 21 out.2009.

WESTPHAL, M. M. F. Promoção da saúde e prevenção de doenças. In: CAMPOS, G.W.S. et al. Tratado de saúde coletiva. São Paulo: Hucitec, 2006, p. 635-667. 


\section{Extended clinic in primary care and subjectification processes: reporting an experience}

The Family Health Strategy focuses on actions to promote health, developed by its professionals along with the community. In the immanence of this group we find lines that develop reflexive processes that can release the production of a creative know-how. In this sense, the inclusion of psychology in the Family Health Support Nucleus (NASF) can contribute to the fulfillment of an expanded clinic in primary health, critical to the so-called healthy models, mostly orthopedic and modeling, open to trials and worried about reconnecting clinic/politics/ production of ways of life. In this paper we question some demands of Family Health teams addressed to the NASF psychologist, their production, ethical and political implications for clinical practice and resulting subjectivity processes. It sought to analyze and map discourses, possible dialogue and assemblages, whose expressions are translated as demands for health professionals. In many cases, these demands express moral considerations, idealized forms of health and well-being. We bet that the construction of the clinic is the product of a collective desire, able to withstand the mechanisms of capture and disciplining of life. This paper proposes that, starting from the daily challenges, the team will be able to discuss, question and become stronger enough to claim healthy ways, free of pre-established standards.

> Key words: family health; psychology; expanded clinic; subjectivicty. 